\title{
The Performance of the Finnish Diabetes Risk Score (FINDRISC) in Detecting Undiagnosed Type 2 Diabetes among Kenyan adults aged 18-69 years
}

Innocent Bambeiha Mugume ( $\sim$ ibmugume@gmail.com )

University of Antwerp

\section{Solomon T Wafula}

Makerere University

Damazo T Kadengye

African Population and Health Research Center

Josefien Van Olmen

University of Antwerp

\section{Research Article}

Keywords: Type 2 Diabetes, undiagnosed Type 2 Diabetes, Prediabetes, Finnish Diabetes Risk Score (FINDRISC), modified FINDRISC, simplified FINDRISC, The Kenya STEPwise survey.

Posted Date: April 27th, 2021

DOI: https://doi.org/10.21203/rs.3.rs-414395/v1

License: (c) (7) This work is licensed under a Creative Commons Attribution 4.0 International License. Read Full License 


\section{Abstract}

Background: Diabetes mellitus is growing to epidemic proportions especially in LMICs. The disease is often undiagnosed until clinical manifestation of related complications. Africa, has the highest proportion of undiagnosed diabetes and in Kenya, is estimated at 53\%. Studies have however demonstrated that early diagnosis \& prevention delays its onset and related complications. Diagnosing \& screening diabetes in Kenya, is however costly and not readily available. The alternative use of diabetes screening risk score tools advocated such as FINDRISC have not been validated for use in Kenya. We therefore aimed to measure the performance of the FINDRISC as a screening tool for undiagnosed type 2 diabetes among Kenya adults.

Methods: A secondary analysis of a Kenya STEPwise cross-sectional survey conducted between April and June 2015 was carried out. The modified FINDRISC and simplified FINDRISC versions were created based on available secondary data and regression analyses performed. Non-parametric analyses of the areas under the receiver operating characteristics curve (AUC), and statistics of the modified FINDRISC and simplified FINDRISC diagnostic tests were analyzed.

Results: A total of 4,027 data observations of individuals aged 18-69 years were analyzed. The prevalence of undiagnosed diabetes and prediabetes were estimated at $1.8 \%$ and $2.6 \%$ respectively. The AUC of the modified FINDRISC and simplified FINDRISC in detecting undiagnosed diabetes were 0.7481 and 0.7486 respectively, with no statistically significant difference $(p=0.9118)$. With an optimal cut-off $\geq 7$, the simplified FINDRISC had a higher PPV (7.9\%) and diagnostic odds (OR:6.65, Cl: $4.43-9.96)$ of detecting undiagnosed T2D than the modified FINDRISC.

Conclusion: The simple and non-invasive modified FINDRISC and simplified FINDRISC tools performed well in detecting undiagnosed diabetes and may be useful in the Kenyan population and other similar population settings. Considering the context of the Kenyan population settings, the simplified FINDRISC is preferred.

\section{Background}

Globally, diabetes mellitus, which refers to a disease that affect how one's body uses blood glucose, is growing to epidemic proportions owing to rising levels of obesity, physical inactivity and inappropriate diet (1). In 2019, global estimates of diabetes among 20-79 year old adults was 463 million, and was projected to rise beyond 700 million by 2045. Type 2 diabetes (T2D) is the most common, accounting for almost $90 \%$ of all diabetes cases worldwide, and results mainly from a confluence of environmental, behavioral and/or genetic factors (2). T2D is often asymptomatic in its earliest stages, with many cases remaining undiagnosed until clinical manifestation of related complications, especially at the micro- and macro- vascular levels (2-4). Africa, has the highest proportion of undiagnosed diabetes at $59.7 \%$ compared to other regions in the world $(2,5)$. In Kenya, the proportion of undiagnosed T2D is estimated at about $53 \%(5,6)$, almost the same as that of the continental average.

Undiagnosed T2D is a major risk factor for death and other severe health complications, such as: blindness, cardiovascular complications, peripheral artery disease, among others (7-9). The economic burden of treating diabetes and its related complications is likewise enormous and, affects household's income and savings, propagating the spiral of ill health and poverty. The loss of productivity and healthcare costs incurred also 
threatens national economies $(10,11)$. However, studies have demonstrated that effective prevention and early detection delays the onset of diabetes and its complications, and prevents associated premature deaths (12, 13). Current diabetes diagnosis and/or targeted screening strategies such as: glycated hemoglobin, fasting plasma or 2-hourly random glucose measurement and point of care capillary blood glucose measurement recommended for use in low and middle income countries (LMICs) (14), are invasive, inconvenient and not feasible for population-wide screening $(15,16)$.

Additionally, health care systems in LMICs especially at primary care settings do not have sufficient human resource and diagnostic capacity to implement recommended diabetes diagnosis and/or screening strategies (17). The use of diabetes risk scores as active community diabetes screening tools have thus been advocated for, to identify high-risk asymptomatic individuals and prevent them from progressing to impaired glucose tolerance or overt diabetes. Among the many diabetes risk score tools developed from different populations to identify individuals at high-risk of developing T2D (18-23), is the Finnish Diabetes Risk Score (FINDRISC). It is the most widely used risk score owing to its validity and ease of applicability.

Although, the FINDRISC has been validated and used as a screening tool across European (24), and in some LMICs $(25,26)$, there is no evidence of its validation and use in Kenya. Population-based diabetes screening by measuring fasting blood glucose is not only a costly and invasive technique, but is also not practical and, not readily available in the community and primary care settings in some LMICs and Kenya in particular $(27,28)$. This study therefore aimed to measure the performance of the FINDRISC in detecting undiagnosed T2D among adults $(18-69)$ years in Kenya.

\section{Methods}

\subsection{Study Design}

The study design, sampling, and implementation of the Kenya STEPwise survey has been described elsewhere (29). In brief, the 2015 Kenya STEPwise survey was a national cross-sectional household survey, designed with the aim of providing estimates for indicators on non-communicable diseases (NCDs) risk factors among adults in Kenya aged 18-69 years between April and June 2015.

\subsection{Study population}

A multi-stage stratified sampling design involving a selection of clusters, households and eligible Individuals was used to select a representative sample of the general adult population of Kenya. The sample size was estimated using a standard formula on the basis of a $50 \%$ prevalence of risk factors as no representative figures were available for the Kenya population at that time. A three stage cluster sample design was used; in the first stage, 200 clusters (100 urban and 100 rural) were selected. In the second stage, a uniform sample of 30 households were selected from the listed households in each cluster, while in the third stage, one individual was randomly selected from all eligible listed household members. With a target of 30 households from each cluster, a minimum sample size of 6,000 individuals was derived to allow for national estimates as per sex and residence (rural or urban). A total of 4500 subjects were successfully interviewed.

To produce unbiased estimates, sampling weights derived from the creation of a fifth National Sample Survey and Evaluation Programme (NASSEP V) master sampling frame from the Kenya National Bureau of Statistics, 
developed using the enumeration areas generated from the 2009 Kenyan Population and Housing Census was used. Participant selection processes were calculated as the inverse of all selection probabilities. Eligible participants were selected using Kish sampling procedure. Inclusion criteria were all those subjects aged 18 to 69 years living in the household selected for more than six months. Exclusion criteria were pregnancy; inability to stand or communicate; or refusal to participate in the survey by not signing the informed consent.

The study protocol was designed in compliance with the Helsinki declaration and approved by the Kenya Medical Research Institute (KEMRI) Ethics Committee. All participants gave informed consent to study procedures prior to primary data collection. For this analysis, approval was obtained from the World Health Organization (WHO) NCD microdata repository (30), and access to data use provided by WHO STEPS team data repository administrator. The present report is presented according to the Strengthening the Reporting of Observational Studies in Epidemiology (STROBE) (31)

\subsection{Data Collection}

The STEPwise data used in this study consisted of Step 1 to Step 3 data. All data collectors were trained on study protocol, human subject protection and supervised during actual data collection. The Step 1 data included: Socio-demographics and self-reports of NCD behavioral risk factors such as: tobacco use, past medical histories of raised blood pressure and diabetes mellitus, physical activity - assessed using Global Physical Activity Questionnaire developed by WHO (32) among others.

Step 2 data comprised of physical measurements: height, weight, blood pressure, waist and hip circumferences. Weight was measured (to the nearest $0.1 \mathrm{kgs}$ ) using a pre-calibrated digital weighing scale (SECA® 877), while participant stood barefoot with light clothing and standing height to the nearest $0.5 \mathrm{~cm}$ using a portable stadiometer (SECA® 877).

Wait circumference (to the nearest $0.5 \mathrm{~cm}$ ) was measured using a constant tension standard tape measure and measurement was taken midway between the lowest rib and iliac crest. Blood pressure measurement was taken with participant in a sitting position using a validated digital blood pressure machine (OMRON M2 device). Three readings were taken 3-5 minutes apart for both systolic and diastolic pressure in accordance with WHO guidelines (33).

Step 3 data were biochemical measurements taken after overnight fasting, and included: total cholesterol, high density lipoprotein cholesterol (HDL-C) and fasting blood glucose (FBG). Finger-prick blood samples were collected and analyzed using a Point of Care CardioCheck® PA analyzer. A total of 4,178 observations of participants that completed Step 3 survey procedures were considered for this secondary analysis. Of those, 15 data observations with age records below 18 years and 136 data observations of records of pregnant participants were excluded leaving a final sample size of 4, 027 data observations.

\subsection{Definitions}

For this study, impaired fasting glycaemia (IFG) was defined as fasting capillary whole blood $\geq 6.1 \mathrm{mmol} / \mathrm{l}$ but less than $7.0 \mathrm{mmol} / \mathrm{I}$ while diabetes mellitus was defined as fasting capillary whole blood $\geq 7.0 \mathrm{mmol} / \mathrm{l}$ (3436). Hypertension was defined as systolic blood pressure $\geq 140 \mathrm{mmHg}$ and diastolic blood pressure $\geq 90$ $\mathrm{mmHg}$ or previous diagnosis of hypertension or taking medication for raised blood pressure (33). Body Mass Index (BMI) was computed by dividing the weight ( $\mathrm{kgs}$ ) by the height in meter squared $\left(\mathrm{m}^{2}\right)$, and used to develop 
categories of underweight, normal weight, overweight and obesity (37). Abdominal obesity was measured as waist circumference $\geq 94 \mathrm{~cm}$ for men and $\geq 80 \mathrm{~cm}$ for women (38). Physical activity was expressed as selfreports of minutes of moderate or vigorous intensive physical activity per week and derived from the WHO Global Physical Activity Questionnaire (32). Dyslipidemia was defined as total cholesterol $\geq 5.0 \mathrm{mmol} / \mathrm{l}$ and/or $\mathrm{HDL}-\mathrm{C}<1.0 \mathrm{mmol} / \mathrm{l}$ in men and $<1.3 \mathrm{mmol} / \mathrm{l}$ in women (39).

\subsection{Original Finnish (FINDRISK) diabetes risk score}

The FINDRISC is a simple diabetes risk score tool original developed in Finland to predict incident diabetes among the Finnish population aged 35-64 years. (insert reference). It's based on eight simple diabetes risk factors including: age (years), BMI $\left(\mathrm{kgs} / \mathrm{m}^{2}\right)$, waist circumference $(\mathrm{cm})$, history of high blood pressure, history of raised blood sugar, family history of diabetes, daily consumption of fruits or vegetables and daily physical activity(20). The tool does not require laboratory investigations, and has different weighted score according to the associated risk, with the final score ranging from 0 to $26(24)$.

\subsection{Statistical Analyses}

All statistical analyses were done using Stata version 14.0 (StataCorp LP, Texas, USA). All data for this analysis were weighted based on the primary data survey weights. Continuous variables were presented as median (IQR), and categorical variables as absolute and weighted frequencies. The prevalence and $95 \%$ confidence interval $(95 \% \mathrm{Cl})$ of IFG and undiagnosed T2D were calculated. Weighted logistic regression analyses were performed and because data were not normally distributed and contained outliers, non-parametric Receiver Operating Characteristic (ROC) curve of the modified and simplified FINDRISC scores were constructed to demonstrate the true positive and false positive relationships and AUC determined. Sensitivity, specificity, diagnostic accuracy, positive predictive values (PPV), negate predictive values (NPV), positive and negative likelihood ratios (LHRs), and diagnostic odds ratio (OR) of the risk score tools were also determined. The optimal cut-off points were determined as the points with the shortest distance in the ROC curve and, calculated as the square root of [ $(1-$ sensitivity $\left.)^{2}+(1-\text { specificity })^{2}\right](40)$.

\subsection{Creating a modified FINDRISC}

Modifications to the original FINDRISC tool were made on the basis of available secondary analysis data. The primary study data collection instrument had no question on parental/family history of diabetes thus, data to that specific risk factor was not collected. However, data to the other FINDRISC tool question components: age, $\mathrm{BMI}$, waist circumference, physical activity, fruit and/or vegetable consumption, personal histories of hypertension and diabetes were collected, and are what were considered in this analysis. The same original FINDRISC score for the different risk factor components were maintained. With this modification, the maximum score of the modified FINDRISC thus reduced from 26 of the original FINDRISC to 20.

\subsection{Creating a simplified FINDRISC}

The modified FINDRISC was further simplified based on logistic regression and ROC curve analyses. Fruit and/or vegetable consumption, and physical activity variables did not significantly influence the AUC in detecting undiagnosed T2D. With this analysis consideration, fruits and/or vegetable consumption and physical activity were excluded, to further simplify the FINDRISC tool. Only age, BMI, waist circumference and histories of diabetes and hypertension were retained, creating a simplified FINDRISC, with a maximum score 18.

\section{Results}




\subsection{Descriptive analysis}

From a total sample of 4500 data observations, a final sample size of 4,027 observations of non-pregnant individuals aged 18-69years (median: 35 [IQR:27 - 47]) were analyzed. Characteristics of participants in terms of FINDRISC risk factors are as shown in Table 1. The weighted prevalence of undiagnosed T2D was $1.8 \%$ and that of prediabetes was $2.6 \%$. According to gender, women had a higher weighted prevalence of undiagnosed T2D (2.4\% [Cl: 1.7-3.3]) and prediabetes (2.8\% [Cl: 2.1-3.8]) than was noted among men (1.3\% [Cl: 0.7-2.3]) and $(2.3 \%$ [Cl: $1.5-3.4])$ respectively. Summary of the descriptive analysis is as indicated in Table 1.

\subsection{Modified FINDRISC}

Overall, the modified FINDRISC scores ranged from 0 to 20, with a median of 3 (IQR:1-6). Participants with undiagnosed T2D had a score range of 0 to 18 , with a median of 9 (IQR:3-12). The median score and IQR differed for both undiagnosed T2D and prediabetes differed across gender. The AUC of the modified FINDRISC in detecting undiagnosed T2D and prediabetes was 0.748 ( $\mathrm{Cl}: 0.692-0.804)$ and 0.631 (Cl: 0.576-0.685) respectively (Table 2).

\subsection{Simplified FINDRISC}

With the simplified FINDRISC, scores ranged from 0 to 18 , with a median of 2 (IQR:0-5). Participants with undiagnosed T2D and prediabetes identified by simplified FINDRISC had a median of 8 (IQR:3-11) and 5 (IQR:1-8) respectively. The AUC of the simplified FINDRISC in detecting undiagnosed T2D and prediabetes was 0.749 (Cl: $0.692-0.805)$ and 0.636 (Cl: $0.583-0.688$ ) respectively. The median score and IQR differed for both undiagnosed T2D and prediabetes across gender (Table 2). However, there was no statistical difference $(\mathrm{P}=$ 0.9118) between the modified and simplified FINDRISC in detecting undiagnosed T2D as shown in Fig. 1.

Table 3 below shows the sensitivity, specificity, diagnostic accuracy, PPV, NPV, LHRs, and the diagnostic OR of six different cut-off points of the modified and simplified FINDRISC if used as tools for screening undiagnosed T2D. With a cut-off of $\geq 7$, the modified FINDRISC had a $2 \%$ higher sensitivity but with a $3.3 \%$ lower specificity level than the simplified FINDRISC. The diagnostic accuracy is the same (0.70) but the simplified FINDRISC had a higher PPV (7.9\%) and diagnostic odds (OR:6.65, Cl: 4.43-9.96) of detecting undiagnosed T2D than the modified FINDRISC.

\section{Discussion}

The FINDRISC tool has largely been validated in Caucasian populations and widely recommended as a simple T2D screening tool across Europe and in other various population settings $(24,41-43)$ but has to a less extent been validated in the African setting (44). Using data from a large national cross-sectional survey, the obtained AUC of the modified and simplified FINDRISC were 0.748 and 0.749 respectively. This performance was lower than the AUC of 0.87 obtained in the first validation study among the Finnish population (20) but better than some other validation studies conducted in: Finland with AUC of 0.727 (24); Bulgaria with AUC of 0.70 (42) and Greece with AUC of 0.724 (41). More so, the performance was again better than the findings from a large primary care study conducted in Spain with AUC of 0.69 (45). This study findings were generally similar to other several validation studies conducted in diverse settings, with AUC ranging between 0.65 and $0.88(41,44,46)$. As such, the FINDRISC can be adopted and utilized in community screening of T2D in Kenya and other similar contexts. 
Although, there are insufficient data on prior FINDRISC use in the African settings, a study from South Africa that used a simplified FINDRISC with only 6 risk factor (age, BIM, waist circumference, personal histories of hypertension and diabetes, and parental/family history of diabetes) in a diverse racial population of Cape Town, had comparable AUC findings of identifying T2D. Similarly, findings from another cross-sectional study conducted in Bostwana had comparable but slightly lower AUC of 0.63 (47). Additionally, findings from a study conducted in Algeria to identify individuals with dysglycemia using FINDRISC was similarly lower, with AUC of 0.64 (48). Despite the low performance of the FINDRISC documented in a few studies conducted in some Africa countries, this study's overall findings of AUC of 0.748 is better than in other contexts, and thus useful in detecting people who might have undiagnosed T2D and should receive a diagnostic test (49).

The observed differences could be in part, attributable to diverse population characteristics and the genetic variants inherent in the African population, and the possible use of different diabetes diagnostic tests such as: glycated hemoglobin, FBG or Oral glucose tolerance test (OGGT) that have varying sensitivities and specificities in different settings $(50,51)$.

At univariate and multivariate analyses, physical activity and fruit or vegetable consumption variables were excluded because they were not associated with undiagnosed T2D. Additionally, a weighted proportion of $1.6 \%$ of those who reported engaging in daily physical activity for at least 30 minutes had undiagnosed T2D and 0.8 $\%$ of those who reported daily consumption of fruits and/or vegetables too had undiagnosed T2D. With these adjustments, there was no statistically significant difference $(P=0.9118)$ between the simplified FINDRISC and the modified FINDRISC in detecting individuals with undiagnosed T2D.

To maximize true positive rates and minimize false negative rates, the optimal cut-off score of the FINDRISC was selected based on the trade-off between sensitivity and specificity, diagnostic accuracy, predictive values and the diagnostic odds. With a cut-off score of $\geq 7$ the simplified FINDRISC had a fairly acceptable sensitivity and specificity and, attained reasonable predictive values and diagnostic odds of detecting more individuals with undiagnosed T2D than with the modified FINDRISC. However, with a cut-off of $\geq 8$, both the modified FINDRISC and simplified FINDRISC had similar diagnostic accuracy as with a cut-off of $\geq 7$ but with lower sensitivity of $55.6 \%$ and $50.5 \%$ respectively. A cut-off score of $\geq 7$ was therefore settled for, sacrificing a few PPV and diagnostic odds points but with a better sensitivity gain.

Using a simplified FINDRISC and the cut-off of 7 or more, $57.6 \%$ of those with a total score $\geq 7$ will be true positive while $83.0 \%$ of those whose total scores $\leq 7$ will be true negatives. On the other hand, using a modified

FINDRISC and its optimal cut-off of 7 or more, $59.6 \%$ will be true positives while $79.7 \%$ will be true negatives. For this study, using a simplified FINDRISC than the modified FINDRISC, and taking the same risk cut-off of 7 or more, the number of people identified for a laboratory test narrowed from 858 (21\%) to $723(18.0 \%)$ and the prevalence of undiagnosed T2D increased from a pre-test probability of $1.8 \%$ to a post-test probability of $7.9 \%$ for simplified FINDRISC compared to $6.9 \%$ for modified FINDRISC.

\section{Study strengths and limitations.}

The main strength of this study is the use of a large national cross-sectional survey data. On the other hand, one of the limitations of this study is that it did not evaluate the detection of future incident diabetes because the STEPwise cross-sectional survey did not provide follow up data. However, FINDRISC was developed to detect undiagnosed diabetes and predict future incident diabetes (20). The other limitation is the use of self-reported 
physical activity and fruit and/or vegetable consumption data among other forms of self-reported data that may have attenuated this study findings. There is also potential uncertainty surrounding the realization of participant fasting glucose state although study procedures required measurement of blood glucose after participant overnight fasting.

\section{Conclusion}

The performance of the modified and simplified FINDRISC in detecting undiagnosed T2D in Kenya was lower than the findings of the original FINDRISC but with an acceptable diagnostic AUC of 0.7486 . With the modifications made to the FINDRISC, the tool can be usefully applied for community screening of diabetes in the Kenyan population and at cut-off score of $\geq 7$ the simplified FINDRISC can reasonably discriminate individuals with diabetes from those without, making diabetes diagnosis more cost effective.

\section{List Of Abbreviations}

T2D: Type 2 diabetes

FINDRISC: Finnish Diabetes Risk Score

NCDs: Non Communicable Diseases

HDL-C: High density lipoprotein cholesterol

FBG: Fasting blood glucose

IFG: Impaired fasting glycaemia

ROC: Receiver operating characteristic curve

AUC: Area under curve

PPV: Positive predictive value

NPV: Negative predictive value

LHRs: Likelihood ratios

BMI: Body mass index

IQR: Interquartile range

WHO: World Health Organization

LMICs: Low middle income countries

NASSEP V: Fifth National Sample Survey and Evaluation Programme

\section{Declarations}




\section{Ethics approval and consent to participants}

Primary survey study approval was obtained from Kenya Medical Research Institute's Ethics Review Committee (SSC No. 2607). Written Informed consent from all subjects was obtained and filed prior to enrollment and collection of data in the primary study. For this secondary data analysis, approval was obtained from WHO STEPS team data repository administrator.

\section{Consent for publication}

Not applicable

\section{Availability of data and materials}

The datasets used and/or analysed during the current study available from the corresponding author on reasonable request.

\section{Competing interests}

The authors declare that they have no known competing interests.

\section{Funding}

Not applicable

\section{Acknowledgement}

We appreciate individuals and institutions that provided technical support for the design and implementation of the main survey. Authors further appreciate the data collection team led by Ministry of Health (MoH) Kenya, WHO and Kenya National Bureau of Statistics (KNBS), Kenya Medical Research Institute (KEMRI) and African Institute for Health and Development (AIHD).

The CORE funding for the main survey was provided by World Bank, WHO, AstraZeneca and MoH/CDC Kenya.

\section{Authors' contributions}

$\mathrm{MBI}$ conceived the study, conducted literature review, applied for data access, did the statistical analysis and drafted the manuscript. DTK and STW reviewed the draft manuscript, provided input and critical comments. JVO provided substantial contribution in reviewing the draft manuscript, provided input and critical comments. All authors read and approved the final manuscript.

\section{Author details}

${ }^{1}$ University of Antwerp, Belgium. ${ }^{2}$ Global Health Institute, University of Antwerp, Belgium.

\section{References}

1. WHO. Non-communicable diseases country profiles 2018. Geneva; 2018 (Available from: https://www.who.int/nmh/publications/ncd-profiles-2018/en/pdf). 2018. 
2. International Diabetes Federation. IDF Diabetes Atlas 2019. (Available from: http://www.idf.org/diabetesatlas). 2019.

3. Chawla A, Chawla R, Jaggi S. Microvasular and macrovascular complications in diabetes mellitus: distinct or continuum? Indian Journal of Endocrinology and Metabolism. 2016;20(4):546.

4. Jones T, L.E. Diabetes Mellitus: the increasing burden of disease in Kenya. South Sudan Medical Journal. 2013;6(3):60-4.

5. Beagley J, Guariguata L, Weil C, Motala AA. Global estimates of undiagnosed diabetes in adults. Diabetes research and clinical practice. 2014;103(2):150-60.

6. Mohamed SF, Mwangi M, Mutua MK, Kibachio J, Hussein A, Ndegwa Z, et al. Prevalence and factors associated with pre-diabetes and diabetes mellitus in Kenya: results from a national survey. BMC public health. 2018;18(Suppl 3):1215-.

7. Papatheodorou K, Banach M, Bekiari E, Rizzo M, Edmonds M. Complications of diabetes 2017. J Diabetes Res. 2018;2018.

8. Stolar M. Glycemic control and complications in type 2 diabetes mellitus. The American Journal of Medicine. 2010;123(3):S3-S11.

9. Smith-Palmer J, Brändle M, Trevisan R, Federici MO, Liabat S, Valentine W. Assessment of the association between glycemic variability and diabetes-related complications in type 1 and type 2 diabetes. Diabetes research and clinical practice. 2014;105(3):273-84.

10. Mapa-Tassou C, Katte J-C, Maadjhou CM, Mbanya JC. Economic Impact of Diabetes in Africa. Current Diabetes Reports. 2019;19(2):5.

11. Abegunde D, Stanciole A. An estimation of the economic impact of chronic noncommunicable diseases in selected countries. World Health Organization, Department of Chronic Diseases and Health Promotion; 2006.

12. Knowler WC, Fowler SE, Hamman RF, Christophi CA, Hoffman HJ, Brenneman AT, et al. 10-year follow-up of diabetes incidence and weight loss in the Diabetes Prevention Program Outcomes Study. Lancet (London, England). 2009;374(9702):1677-86.

13. WHO. Preventing chronic diseases: a vital investment:. Geneva: World Health Organization; 2005. Report No.: 9241563001.

14. WHO. Package of Essential Noncommunicable (PEN) Disease Interventions for Primary Health Care in LowResource Settings. Geneva: World Health Organization; 2011.

15. Icks A, Haastert B, Gandjour A, John J, Lowel H, Holle R, et al. Cost-effectiveness analysis of different screening procedures for type 2 diabetes: the KORA Survey 2000. Diabetes care. 2004;27(9):2120-8.

16. American Diabetes A. Screening for type 2 diabetes. Diabetes care. 2004;27 Suppl 1:S11-4.

17. Nuche-Berenguer B, Kupfer LE. Readiness of sub-Saharan Africa healthcare systems for the new pandemic, diabetes: a systematic review. J Diabetes Res. 2018;2018.

18. Heikes KE, Eddy DM, Arondekar B, Schlessinger L. Diabetes Risk Calculator: a simple tool for detecting undiagnosed diabetes and pre-diabetes. Diabetes care. 2008;31(5):1040-5.

19. Hippisley-Cox J, Coupland C, Robson J, Sheikh A, Brindle P. Predicting risk of type 2 diabetes in England and Wales: prospective derivation and validation of QDScore. BMJ (Clinical research ed). 2009;338:b880. 
20. Lindstrom J, Tuomilehto J. The diabetes risk score: a practical tool to predict type 2 diabetes risk. Diabetes care. $2003 ; 26(3): 725-31$.

21. Joshi SR. Indian Diabetes Risk Score. The Journal of the Association of Physicians of India. 2005;53:755-7.

22. Guasch-Ferre M, Bullo M, Costa B, Martinez-Gonzalez MA, Ibarrola-Jurado N, Estruch R, et al. A risk score to predict type 2 diabetes mellitus in an elderly Spanish Mediterranean population at high cardiovascular risk. PloS one. 2012;7(3):e33437.

23. Doi Y, Ninomiya T, Hata J, Hirakawa Y, Mukai N, Iwase M, et al. Two risk score models for predicting incident Type 2 diabetes in Japan. Diabetic Medicine. 2012;29(1):107-14.

24. Saaristo T, Peltonen M, Lindstrom J, Saarikoski L, Sundvall J, Eriksson JG, et al. Cross-sectional evaluation of the Finnish Diabetes Risk Score: a tool to identify undetected type 2 diabetes, abnormal glucose tolerance and metabolic syndrome. Diabetes and Vascular Disease Research. 2005;2(2):67-72.

25. Metonnou-Adanhoume C, Agueh V, Azandjeme C, Sossa C, Kpozehouen A, Hessou J, et al. Optimal Threshold of the Finnish Diabetes Risk Score (Findrisc) for Screening at-Risk Adults in an African Population in Southern Benin. Universal Journal of Public Health. 2019.

26. Ku GM, Kegels G. The performance of the Finnish Diabetes Risk Score, a modified Finnish Diabetes Risk Score and a simplified Finnish Diabetes Risk Score in community-based cross-sectional screening of undiagnosed type 2 diabetes in the Philippines. Primary care diabetes. 2013;7(4):249-59.

27. Browna E, Natolia N, McLaughlina R, Mehtaa K. Pathways and Barriers to Diabetes Screening: Observations from Rural Kenya. Procedia Engineering. 2015;107:387-94.

28. Manne-Goehler J, Atun R, Stokes A, Goehler A, Houinato D, Houehanou C, et al. Diabetes diagnosis and care in sub-Saharan Africa: pooled analysis of individual data from 12 countries. The lancet Diabetes Endocrinology. 2016;4(11):903-12.

29. Ministry of Health, Kenyan National Bureau of Statistics, WHO. Kenya STEPwise Survey for NonCommunicable Diseases Risk Factors 2015 Report:; 2015.

30. World Health Organization. NCD Microdata Repository. (Available from:

https://extranet.who.int/ncdsmicrodata/index.php/home) 2019 [

31. von Elm E, Altman DG, Egger M, Pocock SJ, Gøtzsche PC, Vandenbroucke JP. The Strengthening the Reporting of Observational Studies in Epidemiology (STROBE) statement: guidelines for reporting observational studies. PLoS medicine. 2007;4(10):e296.

32. WHO. Global physical activity questionnaire (GPAQ) analysis guide. Geneva2012 [Available from: http://www.who.int/chp/steps/resources/GPAQ_Analysis_Guide.pdf.

33. Alderman M, Arakawa K, Beilin L, Chalmers J, Erdine S, Fujishima R, et al. 1999 World Health OrganizationInternational Society of Hypertension Guidelines for the Management of Hypertension. Journal of Hypertension. 1999;8:9-43.

34. Ligthart S, van Herpt TT, Leening MJ, Kavousi M, Hofman A, Stricker BH, et al. Lifetime risk of developing impaired glucose metabolism and eventual progression from prediabetes to type 2 diabetes: a prospective cohort study. The lancet Diabetes Endocrinology. 2016;4(1):44-51.

35. WHO. Definition and diagnosis of diabetes mellitus and intermediate hyperglycaemia: report of a WHO/IDF consultation. . Geneva; 2006. 
36. American Diabetes Association. Diagnosis and classification of diabetes mellitus. Diabetes care. 2011;34 Suppl 1(Suppl 1):S62-S9.

37. National Institute of Health. The practical guide: identification, evaluation, and treatment of overweight and obesity in adults. Bethesda, Maryland2000 [Available from:

https://www.nhlbi.nih.gov/files/docs/guidelines/prctgd_c.pdf.

38. WHO. Waist circumference and waist-hip ratio : report of a WHO expert consultation, Geneva, 8-11 December 2008. Geneva: World Health Organization; 2011.

39. Cleeman J, Grundy S, Becker D, Clark L, Cooper R, Denke M, et al. cholesterol Educ program, executive summary of the third report of the national cholesterol education program (NCEP) expert panel on detection, evaluation, and treatment of high blood cholesterol in adults (adult treatment panel III). Journal of American Medical Association. 2001;285:2486-97.

40. Perkins NJ, Schisterman EF. The inconsistency of "optimal" cutpoints obtained using two criteria based on the receiver operating characteristic curve. American Journal of Epidemiology. 2006;163(7):670-5.

41. Makrilakis K, Liatis S, Grammatikou S, Perrea D, Stathi C, Tsiligros P, et al. Validation of the Finnish diabetes risk score (FINDRISC) questionnaire for screening for undiagnosed type 2 diabetes, dysglycaemia and the metabolic syndrome in Greece. Diabetes and Metabolism. 2011;37(2):144-51.

42. Tankova T, Chakarova N, Atanassova I, Dakovska L. Evaluation of the Finnish Diabetes Risk Score as a screening tool for impaired fasting glucose, impaired glucose tolerance and undetected diabetes. Diabetes research and clinical practice. 2011;92(1):46-52.

43. Soriguer F, Valdés S, Tapia MJ, Esteva I, Ruiz de Adana MS, Almaraz MC, et al. [Validation of the FINDRISC (FINnish Diabetes RIsk SCore) for prediction of the risk of type 2 diabetes in a population of southern Spain. Pizarra Study]. Med Clin (Barc). 2012;138(9):371-6.

44. Mbanya V, Hussain A, Kengne AP. Application and applicability of non-invasive risk models for predicting undiagnosed prevalent diabetes in Africa: A systematic literature search. Primary care diabetes. 2015;9(5):317-29.

45. Costa B, Barrio F, Piñol JL, Cabré JJ, Mundet X, Sagarra R, et al. Shifting from glucose diagnosis to the new $\mathrm{HbA} 1 \mathrm{c}$ diagnosis reduces the capability of the Finnish Diabetes Risk Score (FINDRISC) to screen for glucose abnormalities within a real-life primary healthcare preventive strategy. BMC Medicine. 2013;11(1):45.

46. Zhang L, Zhang Z, Zhang Y, Hu G, Chen L. Evaluation of Finnish Diabetes Risk Score in screening undiagnosed diabetes and prediabetes among US adults by gender and race: NHANES 1999-2010. PloS one. $2014 ; 9(5)$.

47. Omech B, Mwita JC, Tshikuka J-G, Tsima B, Nkomazna O, Amone-P'Olak K. Validity of the Finnish Diabetes Risk Score for Detecting Undiagnosed Type 2 Diabetes among General Medical Outpatients in Botswana. J Diabetes Res. 2016;2016:4968350-.

48. Azzouz M, Boudiba A, Guerchani M-K, Lyes Y, Hannachi R, Baghous $H$, et al. Apport du score de risque finlandais FINDRISC dans l'identification de la dysglycémie dans une population algéroise, Algérie. Médecine des Maladies Métaboliques. 2014;8(5):532-8.

49. Hanley JA, McNeil BJ. The meaning and use of the area under a receiver operating characteristic (ROC) curve. Radiology. 1982;143(1):29-36. 
50. Rohlfing CL, Little RR, Wiedmeyer HM, England JD, Madsen R, Harris Ml, et al. Use of GHb (HbA1c) in screening for undiagnosed diabetes in the U.S. population. Diabetes care. 2000;23(2):187-91.

51. Bennett CM, Guo M, Dharmage SC. HbA1c as a screening tool for detection of Type 2 diabetes: a systematic review. Diabetic Medicine. 2007;24(4):333-43.

\section{Tables}


Table 1

Characteristics of study participants, according to normal fasting glucose, impaired fasting glucose and diabetes.

\begin{tabular}{|c|c|c|c|c|c|c|}
\hline & \multirow[t]{2}{*}{$\begin{array}{l}\text { Missing } \\
(\%)\end{array}$} & \multirow{2}{*}{$\begin{array}{l}\text { Gender } \\
\text { (M/F) }\end{array}$} & \multirow[t]{2}{*}{$\begin{array}{l}\text { All, } n= \\
4,027\end{array}$} & \multirow{2}{*}{$\begin{array}{l}\text { Normoglycemia, } \\
\text { n (weighted \%) } \\
3,805 \text { (95.6) }\end{array}$} & \multicolumn{2}{|c|}{$\begin{array}{l}\text { Elevated fasting blood } \\
\text { glucose }\end{array}$} \\
\hline & & & & & $\begin{array}{l}\text { Prediabetes } \\
\text { n (weighted } \\
\%) \\
123(2.6)\end{array}$ & $\begin{array}{l}\text { Diabetes } \\
\text { n } \\
\text { (weighted } \\
\% \text { ) } \\
99(1.8)\end{array}$ \\
\hline $\begin{array}{l}\text { Proportion/Prevalence [ } \\
95 \% \mathrm{Cl}]\end{array}$ & & & & $\begin{array}{l}95.6 \%[94.4- \\
96.5]\end{array}$ & $\begin{array}{l}2.6 \%[1.9- \\
3.4]\end{array}$ & $\begin{array}{l}1.8 \% \\
{[1.3-2.6]}\end{array}$ \\
\hline $\begin{array}{l}\text { Gender distribution, } \\
\text { Proportion/Prevalence [ } \\
95 \% \mathrm{Cl}]\end{array}$ & & $\begin{array}{l}M \\
F\end{array}$ & $\begin{array}{l}50.6 \% \\
{[47.8-} \\
53.4] \\
\\
49.4 \% \\
{[46.6-} \\
52.2]\end{array}$ & $\begin{array}{l}96.4 \%[95.0- \\
97.4] \\
94.7 \%[93.3- \\
95.9]\end{array}$ & $\begin{array}{l}2.3 \%[1.5- \\
3.4] \\
2.8 \%[2.1- \\
3.8]\end{array}$ & $\begin{array}{l}1.3 \% \\
{[0.7-2.3]} \\
2.4 \% \\
{[1.7-3.3]}\end{array}$ \\
\hline Age (years) & & $\begin{array}{l}M \\
F\end{array}$ & $\begin{array}{l}36(27- \\
47) \\
35(27- \\
47)\end{array}$ & $\begin{array}{l}35(27-46) \\
35(27-46)\end{array}$ & $\begin{array}{l}40(30- \\
56) \\
37(29- \\
58)\end{array}$ & $\begin{array}{l}44(35- \\
55) \\
51(40- \\
60)\end{array}$ \\
\hline BMI $\left(\mathrm{kgs} / \mathrm{m}^{2}\right)$ & $\begin{array}{l}14 \\
(0.35)\end{array}$ & $\begin{array}{l}M \\
F\end{array}$ & $\begin{array}{l}21.6 \\
(19.5- \\
24.0) \\
23.5 \\
(20.4- \\
27.5)\end{array}$ & $\begin{array}{l}21.6(19.5- \\
23.9) \\
23.3(20.3- \\
27.2)\end{array}$ & $\begin{array}{l}21.1(19.1 \\
-26.2) \\
24.2(21.4 \\
-29.4)\end{array}$ & $\begin{array}{l}23.0 \\
(18.5- \\
26.8) \\
27.9 \\
(23.7- \\
30.5)\end{array}$ \\
\hline $\begin{array}{l}\text { Waist circumference } \\
(\mathrm{cm})\end{array}$ & $8(0.2)$ & $\begin{array}{l}M \\
F\end{array}$ & $\begin{array}{l}78.0 \\
(72.0- \\
85.0) \\
79.5 \\
(72.0- \\
89.0)\end{array}$ & $\begin{array}{l}78.0(72.0- \\
85.0) \\
79.0(71.5- \\
88.0)\end{array}$ & $\begin{array}{l}81.3(74.0 \\
-91.0) \\
85.0(76.0 \\
-94.0)\end{array}$ & $\begin{array}{l}81.0 \\
(71.5- \\
95.0) \\
90.0 \\
(75.0- \\
99.0)\end{array}$ \\
\hline
\end{tabular}

Data are presented as median (IQR), IQR: Inter Quartile Range; and n (weighted \%) unless otherwise specified; BMI: Body Mass Index; BP: Blood Pressure; FBG: Fasting Blood Glucose; n: count number; Cl: Confidence Interval. 


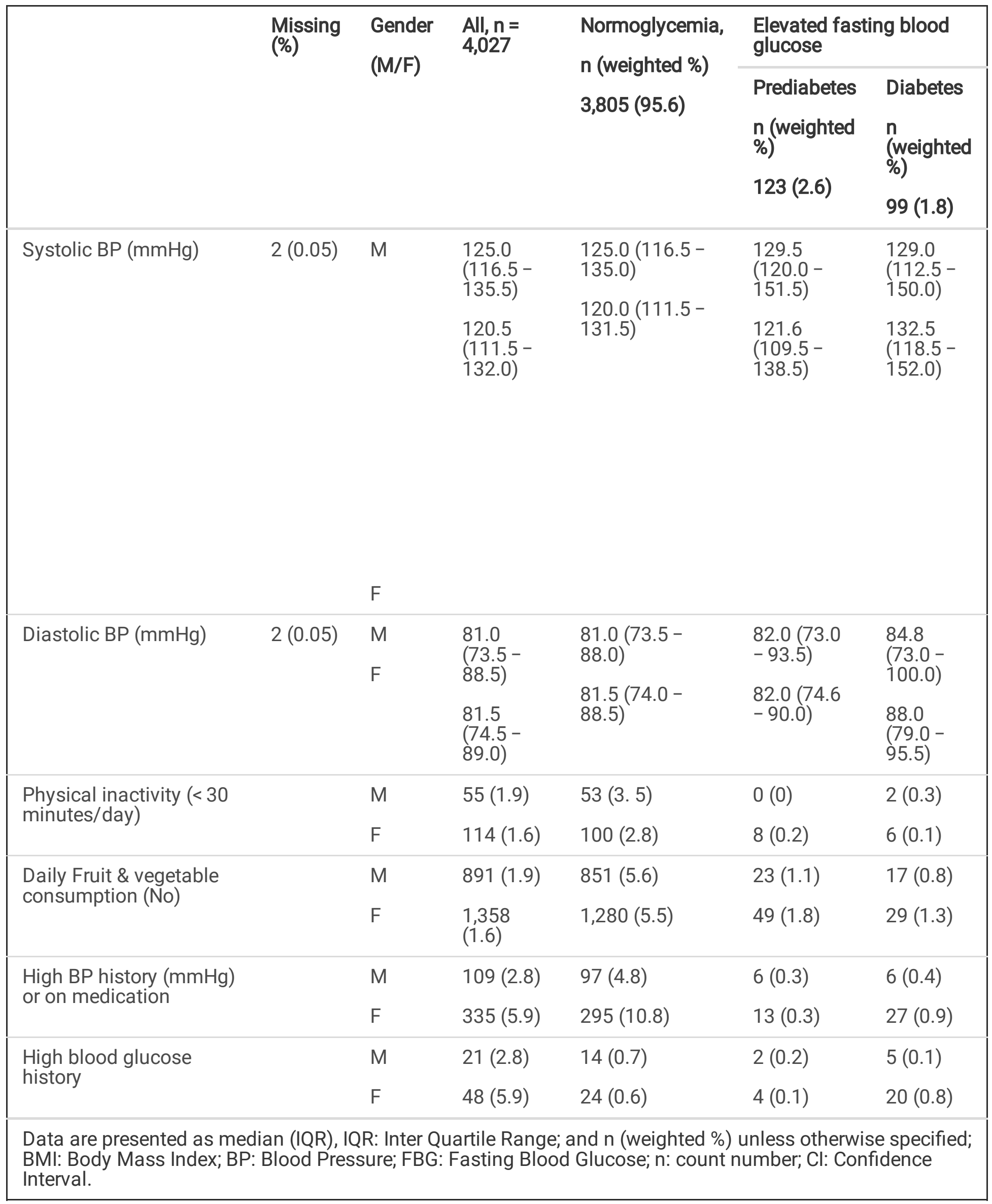


Table 2

Modified and simplified Finnish Risk Score according to normal fasting glucose, impaired fasting glucose and diabetes.

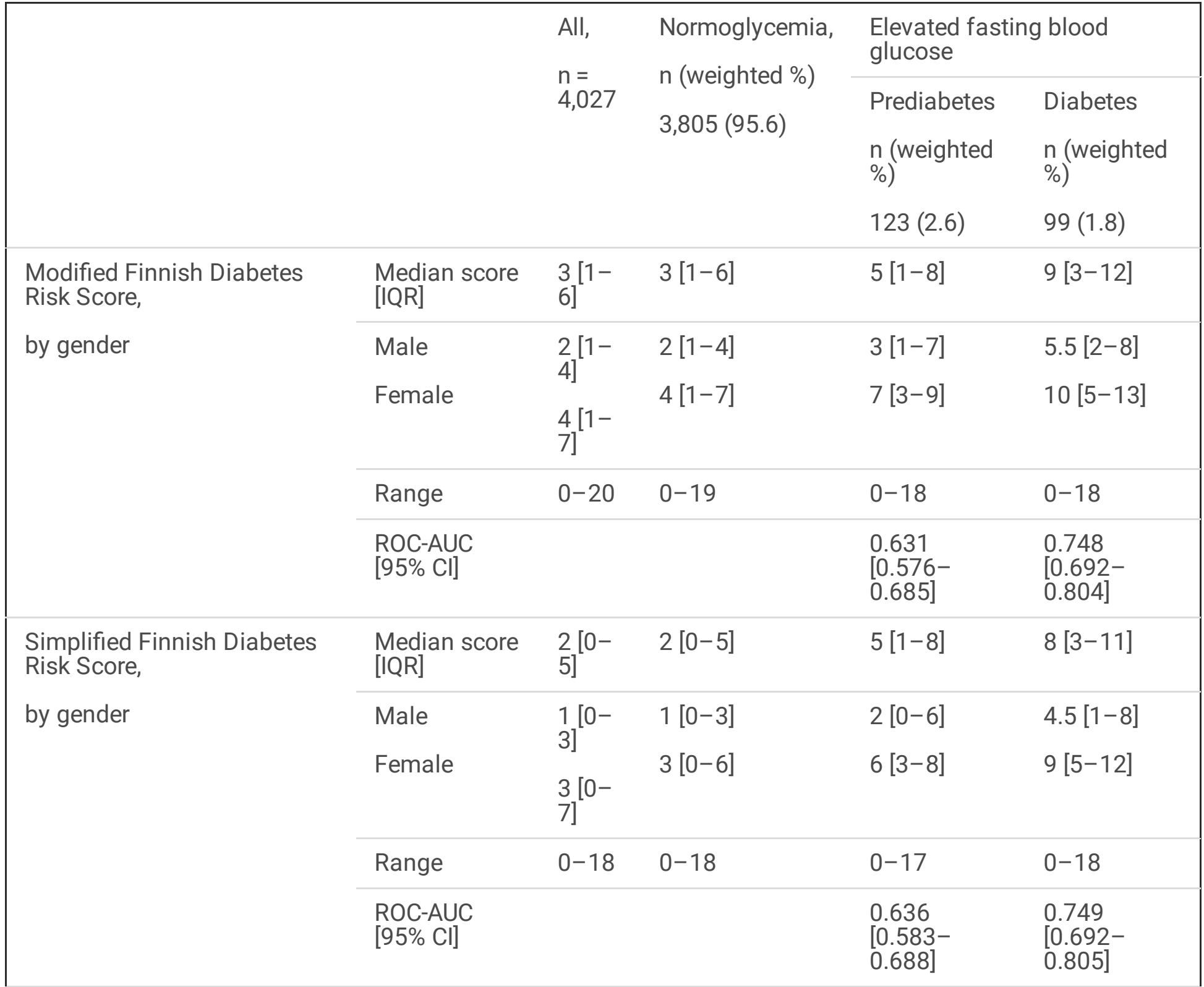

95\% Cl: Confidence Interval; n: counts; ROC-AUC: area under the receiver operating characteristics curve. 
Table 3

Sensitivity, specificity, AUC, predictive values likelihood ratios and diagnostic odds ratios of different cut-off points of the modFINDRISC and simpFINDRISC in the diagnosis of undiagnosed diabetes.

\begin{tabular}{|c|c|c|c|c|c|c|c|c|c|c|}
\hline \multirow[t]{2}{*}{$\begin{array}{l}\text { Cut- } \\
\text { off }\end{array}$} & \multirow{2}{*}{$\begin{array}{l}\mathrm{N}, \\
\text { Population } \\
\text { Identified } \\
\text { (\% tot pop) }\end{array}$} & \multirow[t]{2}{*}{$\begin{array}{l}\text { Sensitivity } \\
\text { (\%) }\end{array}$} & \multirow[t]{2}{*}{$\begin{array}{l}\text { Specificity } \\
(\%)\end{array}$} & \multirow[t]{2}{*}{$\begin{array}{l}\text { Diagnostic } \\
\text { accuracy }\end{array}$} & \multirow[t]{2}{*}{$\begin{array}{l}\text { PPV } \\
\text { (\%) }\end{array}$} & \multirow[t]{2}{*}{$\begin{array}{l}\text { NPV } \\
(\%)\end{array}$} & \multirow[t]{2}{*}{$\begin{array}{l}(+) \\
\mathrm{LR}\end{array}$} & \multirow[t]{2}{*}{$\begin{array}{l}(-) \\
\mathrm{LR}\end{array}$} & \multicolumn{2}{|c|}{$\begin{array}{l}\text { Diagnostic } \\
\text { Odds }\end{array}$} \\
\hline & & & & & & & & & OR & $\begin{array}{l}95 \% \\
\mathrm{Cl}\end{array}$ \\
\hline \multicolumn{11}{|c|}{ Modified FINDRISC } \\
\hline$\geq 4$ & $\begin{array}{l}1,764 \\
(43.8)\end{array}$ & 72.7 & 56.9 & 0.65 & 4.1 & 98.8 & 1.69 & 0.35 & 3.52 & $\begin{array}{l}2.26- \\
5.49\end{array}$ \\
\hline$\geq 5$ & $\begin{array}{l}1,417 \\
(35.2)\end{array}$ & 69.7 & 65.7 & 0.68 & 4.9 & 98.9 & 2.03 & 0.46 & 4.40 & $\begin{array}{l}2.86- \\
6.77\end{array}$ \\
\hline$\geq 6$ & $\begin{array}{l}1,110 \\
(27.6)\end{array}$ & 64.6 & 73.4 & 0.69 & 5.8 & 98.8 & 2.43 & 0.48 & 5.04 & $\begin{array}{l}3.33- \\
7.63\end{array}$ \\
\hline$\geq 7$ & $858(21.3)$ & 59.6 & 79.7 & 0.70 & 6.9 & 98.7 & 2.93 & 0.51 & 5.78 & $\begin{array}{l}3.85- \\
8.67\end{array}$ \\
\hline$\geq 8$ & $638(15.8)$ & 55.6 & 85.2 & 0.70 & 8.6 & 98.7 & 3.74 & 0.52 & 7.17 & $\begin{array}{l}4.79- \\
10.74\end{array}$ \\
\hline$\geq 9$ & $472(11.7)$ & 49.5 & 89.2 & 0.69 & 10.9 & 98.6 & 4.60 & 0.57 & 8.12 & $\begin{array}{l}5.42- \\
12.17\end{array}$ \\
\hline \multicolumn{11}{|c|}{ Simplified FINDRISC } \\
\hline$\geq 4$ & $\begin{array}{l}1,531 \\
(38.0)\end{array}$ & 72.7 & 62.9 & 0.68 & 4.7 & 98.9 & 1.96 & 0.43 & 4.51 & $\begin{array}{l}2.90- \\
7.03\end{array}$ \\
\hline$\geq 5$ & $\begin{array}{l}1,219 \\
(30.3)\end{array}$ & 67.7 & 70.7 & 0.69 & 5.5 & 98.9 & 2.31 & 0.46 & 5.05 & $\begin{array}{l}3.30- \\
7.71\end{array}$ \\
\hline$\geq 6$ & $920(22.8)$ & 58.6 & 78.1 & 0.68 & 6.3 & 98.7 & 2.67 & 0.53 & 5.03 & $\begin{array}{l}3.36- \\
7.54\end{array}$ \\
\hline$\geq 7$ & $723(18.0)$ & 57.6 & 83.0 & 0.70 & 7.9 & 98.7 & 3.40 & 0.51 & 6.65 & $\begin{array}{l}4.43- \\
9.96\end{array}$ \\
\hline$\geq 8$ & $484(12.0)$ & 50.5 & 88.0 & 0.70 & 10.4 & 98.6 & 4.57 & 0.56 & 8.21 & $\begin{array}{l}5.48- \\
12.31\end{array}$ \\
\hline$\geq 9$ & $396(9.8)$ & 43.4 & 91.0 & 0.67 & 10.9 & 98.5 & 4.83 & 0.62 & 7.78 & $\begin{array}{l}5.16- \\
11.72\end{array}$ \\
\hline
\end{tabular}

\section{Figures}




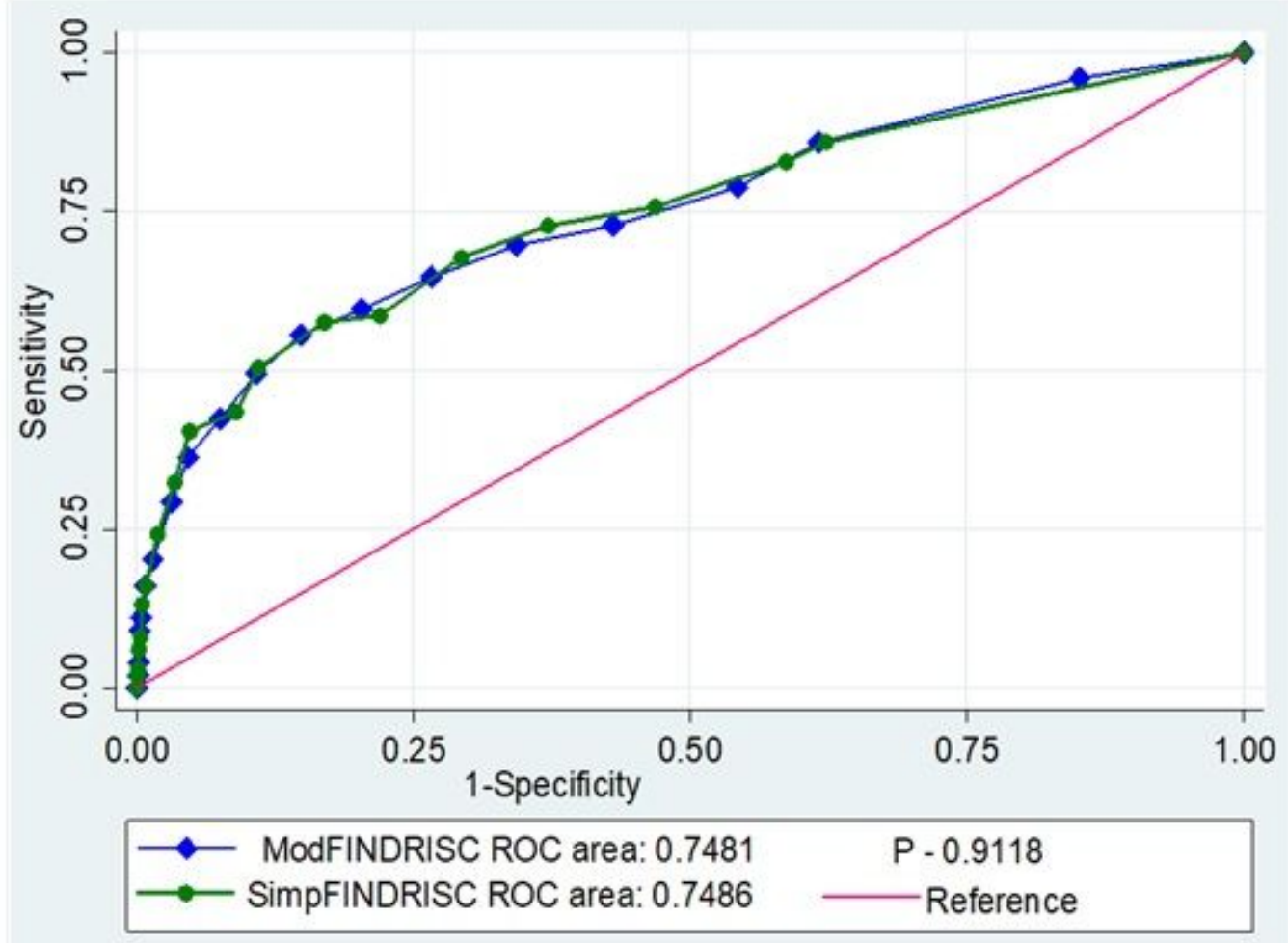

Figure 1

ROC comparison between modified FINDRISC and simplified FINDRISC

\section{Supplementary Files}

This is a list of supplementary files associated with this preprint. Click to download.

- AppendixA.pdf 